\title{
First record of male combat in Oligodon fasciolatus
}

\author{
HARRY WARD-SMITH ${ }^{1 *}$, ROSE STROUP ${ }^{1}$ \& BARTOSZ NADOLSKI ${ }^{2}$ \\ ${ }^{1}$ Sakaerat Conservation and Snake Education Team, Nakhon Ratchasima, Thailand \\ ${ }^{2}$ Suranaree University of Technology, Nakhon Ratchasima, Thailand \\ *Corresponding author e-mail: harry_ws@hotmail.co.uk
}

$T^{\mathrm{T}}$ he banded kukri snake (Oligodon fasciolatus) is a primarily nocturnal, terrestrial species that reaches a maximum length of $920 \mathrm{~mm}$ in males and $863 \mathrm{~mm}$ in females. It is typically grey in colour but may vary from red to brown. Encountered throughout mainland south-east Asia, this species is a habitat generalist being found in agricultural landscapes and tropical forests up to $900 \mathrm{~m}$ asl (Cox et al., 2012). Oligodon species possess enlarged posterior maxillary teeth that evolved to slice through a specialised diet of frogs and reptile eggs. This dentition results in bites that are characterised by deep, clean, bloody wounds.

Herein we present only the second report of combat between males in the genus Oligodon; with a historic report in Oligodon taeniatus recently being uncovered (Gray, 2021). During a herpetofaunal survey on the 26th December 2018 in Sakaerat Biosphere Reserve, Nakhon Ratchasima, Thailand $\left(14.5025^{\circ} \mathrm{N}, 101.9248^{\circ} \mathrm{E}\right.$, Datum 47P, $511 \mathrm{~m}$ asl), we observed two adult male $O$. fasciolatus engaged in combat; shown in our photographs (Figs. $1 \& 2$ ) and our video (BHS video, 2021). The snakes were $5 \mathrm{~m}$ from the road within dry evergreen forest, consisting of little ground vegetation and a thick layer of dry fallen leaves. The battle occurred just after sunset (17:50 h), with an ambient temperature of $25^{\circ} \mathrm{C}$ and $72 \%$ relative humidity.

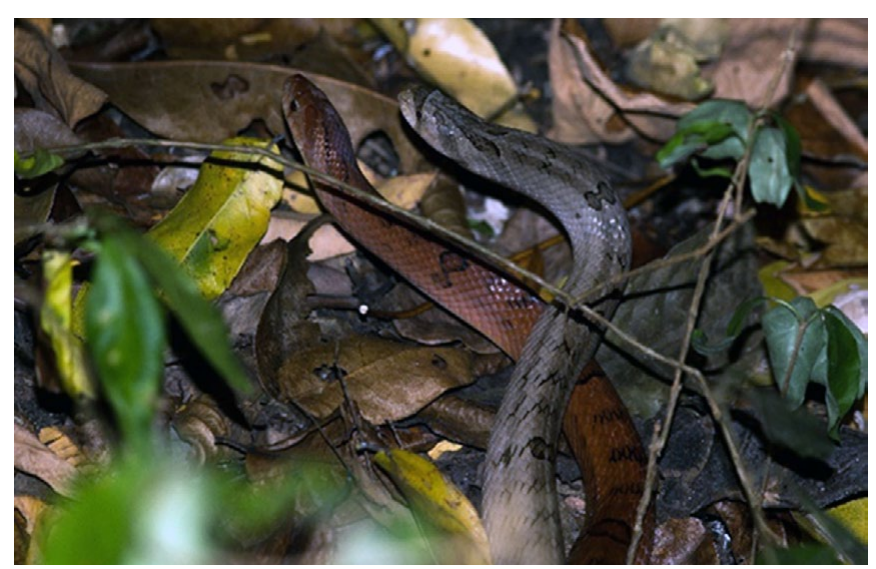

Figure 1. Two male Oligodon fasciolatus engaged in combat, exhibiting mounting behaviour

The authors' attention was first drawn to the snakes by the rustling of dry leaves as they fought. Combat continued as the presence of observers was ignored. The battle was characterised by raised heads and coiling around each other

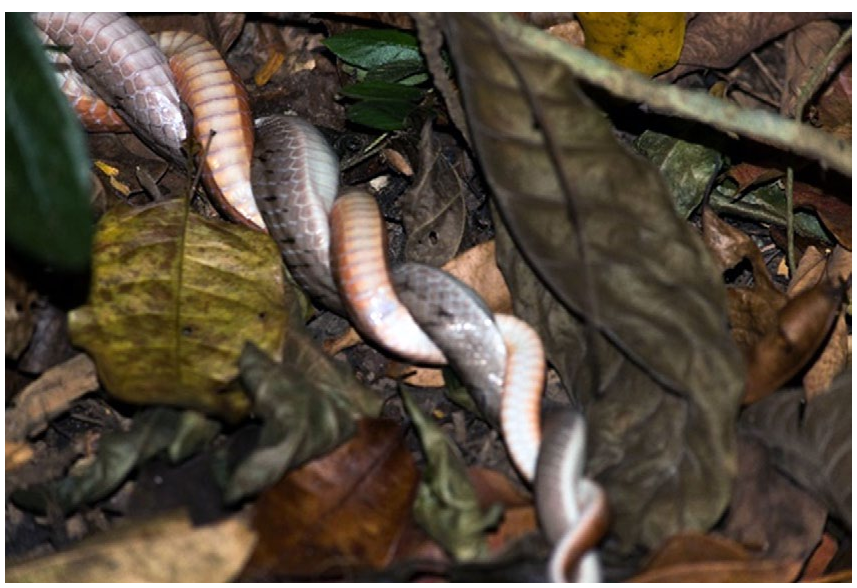

Figure 2. The posteriors of two male Oligodon fasciolatus tightly entwined during combat

with their posteriors tightly entwined (Fig 2). From here each snake attempted to mount and press downward on the other with its head and neck (Fig 1). All movement was slow and graceful until one became pinned, where it would quickly jerk its head to the side to get free. This sequence of behaviour continued with the position of dominance switching between the two males. Combat continued until 18:10 $\mathrm{h}$, where they broke apart and moved in different directions, with no sign of an apparent winner. Both specimens were caught and processed using isoflurane anaesthesia via inhalation and then released back to their place of capture within 24 $h$, permitted under: National Research Council of Thailand $110 / 61$. Both individuals were probed and confirmed to be male, with a total length of $858 \mathrm{~mm}, 189.7 \mathrm{~g}$ (grey male) and $839 \mathrm{~mm}, 171.7 \mathrm{~g}$ (red male).

Although biting is common in the male combat of many nonvenomous snake species, no bite wounds were observed nor found when the males were examined. An explanation for this may be attributed to the trauma inflicted from bites of this species. As with male combat in venomous species, the males may not be trying to incapacitate their opponent, just show dominance in intrasexual competition (Shine, 1994). This contrasts to intraspecific territorial behaviour over turtle nest food resources, where Huang et al. (2011) observed biting between Oligodon formosanus.

Intraspecific male combat in Old World colubrids has rarely been observed, particularly never in a small bodied semi-fossorial species. Shine $(1978,1994)$ predicted that in 
all snakes where males grow larger than females, there will prove to be competitive interactions between reproductive males. This observation provides additional evidence for this prediction as male 0 . fasciolatus grow $\sim 7 \%$ larger than females. This observation contributes to the growing body of knowledge that male combat occurs in a greater number of snake species than previously thought, furthering our knowledge of the evolution of courtship and combat in snakes, with particular attention to its presence and rarity in smaller taxa (Senter et al., 2014).

\section{ACKNOWLEDGMENTS}

We thank Anji D'souza as supervisor and leader of the Green Cat Snake Project where during these surveys this observation was made and to the Sakaerat Environmental Research Station for their support and housing throughout our stay. We thank Curtis Radcliffe for his support in collecting biometric data of described individuals.

\section{REFERENCES}

BHS video (2021). First record of male combat in the kukri snake Oligodon fasciolatus. https://youtu.be/smslaX-S9GY
Cox, M.J., Hoover, M.F., Lawan, C. \& Kumthorn, T. (2012). The Snakes of Thailand. Chulalongkorn University Museum of National History. 275-278pp

Gray, R.J. (2021) Male combat in the striped kukri snake Oligodon teniatus. Herpetological Bulletin 155: 30-31.

Huang, W.S., Greene, H.W., Chang, T.J. \& Shine, R. (2011). Territorial behavior in Taiwanese kukrisnakes (Oligodon formosanus). Proceedings of the National Academy of Sciences 108: 7455-7459.

Senter, P., Harris, S.M. \& Kent, D.L. (2014). Phylogeny of courtship and male-male combat behavior in snakes. PloS one 9: p.e107528.

Shine, R. (1978). Sexual size dimorphism and male combat in snakes. Oecologia 33: 269-277.

Shine, R. (1994). Sexual size dimorphism in snakes revisited. Copeia: 326-346.

Accepted: 18 December 2020 